\title{
Radicale cystectomie als gouden standaard: open of robotgeassisteerd?
}

\author{
Anna M. Leliveld · Carl J. Wijburg • Geert A.H.J. Smits
}

Published online: 25 November 2015

(C) The Author(s) 2015. This article is published with open access at Springerlink.com

Samenvatting De open radicale cystectomie wordt beschouwd als de standaardbehandeling van het spierinvasief blaascarcinoom en bij recidiverend hoogrisico niet-spierinvasief blaascarcinoom. Sinds 2000 wordt de cystectomie steeds meer laparoscopisch en met assistentie van de robot uitgevoerd, al dan niet met een intracorporeel aangelegde urinedeviatie. De resultaten uit de literatuur komen vooral uit retrospectieve studies, waarin de resultaten worden vergeleken met historische open cystectomieseries. In combinatie met de resultaten van enkele kleinere prospectieve series is er aanzienlijk bewijs dat de robotgeassisteerde radicale cystectomie (RARC) een veilige techniek is waarbij minder bloedverlies en bloedtransfusiebehoefte optreedt en patiënten minder lang opgenomen zijn ten opzichte van de open radicale cystectomie (ORC). Ten aanzien van de functionele en oncologische resultaten lijkt de RARC niet onder te doen voor de ORC. Daarbij heeft de RARC een groot ergonomisch voordeel. Een nadeel is dat de aanschaf en het gebruik van een $\mathrm{daVinci}^{\mathrm{TM}}$-systeem gepaard gaan met hogere kosten.

Zowel internationaal als nationaal wordt momenteel gewerkt aan prospectieve multicentrische vergelijkende studies om het mogelijke verschil aan te tonen ten opzichte van de ORC op het oncologische en/of functionele vlak, maar daarnaast meer duidelijkheid te verkrijgen ten aanzien van de kosteneffectiviteit van de RARC.

dr. A.M. Leliveld $(\bowtie)$

afdeling Urologie, Universitair Medisch Centrum Groningen, Groningen, Nederland

e-mail: a.m.leliveld@umcg.nl

C.J. Wijburg · G.A.H.J. Smits afdeling Urologie, Rijnstate,

Arnhem, Nederland
Trefwoorden radicale cystectomie .

robotgeassisteerd $\cdot$ spierinvasief blaascarcinoom

\section{Golden standard for radical cystectomy: open or robot assisted?}

\begin{abstract}
The open radical cystectomy is considered the golden standard treatment for muscle invasive bladder cancer and recurrent high risk non-muscle invasive bladder cancer. Since 2000 there is an increase in the performance of laparoscopic and robotic assisted cystectomy with or without the creation of an intracorporal performed urine deviation. The results from literature mainly present retrospective studies reflecting comparison with historical open cystectomy series. In combination with few smaller prospective series there is ample evidence for RARC as a safe technique, accompanied with less blood loss and transfusion rates and shorter admission time, compared to the ORC. Concerning the functional and oncological results the RARC seems not inferior to the ORC. In addition, the RARC has a great ergonomic benefit. As a drawback the higher costs for purchase and use of the daVinci ${ }^{\mathrm{TM}}$ system can be mentioned. Nowadays, international and national studies are being developed to gain more evidence to show potential difference over the ORC as well as to clarify the concerns about the cost-effectiveness of the RARC
\end{abstract}

Keywords radical cystectomy robot assisted

muscle invasive bladder cancer 


\section{Introductie}

Blaaskanker is de meest voorkomende maligniteit van de urinewegen. In Nederland worden jaarlijks meer dan 6000 patiënten gediagnosticeerd met urotheelcelcarcinoom van de blaas (zie www.cijfersoverkanker.nl). Het betreft een oudere leeftijdsgroep; mannen worden in vergelijking tot vrouwen vier keer vaker getroffen. In eerste instantie wordt bij $70 \%$ van de nieuwe patiënten een niet-spierinvasief blaascarcinoom vastgesteld en bij ongeveer $30 \%$ een spierinvasieve vorm. In de eerste groep is er een risico tot $45 \%$ (overall 10-15\%), afhankelijk van de specifieke kenmerken, dat het eventuele recidief niet meer op intravesicale therapie respondeert of alsnog een spierinvasieve vorm wordt. De mortaliteit ten gevolge van blaaskanker in Nederland is de laatste 20 jaar slechts marginaal gedaald.

\section{Radicale cystectomie - indicatie en alternatieven}

Bij patiënten met een recidiverend hoogrisico niet-spierinvasief blaascarcinoom of een primair spierinvasief blaascarcinoom dient een meer radicale behandeling plaats te vinden. In de jaren 50 van de vorige eeuw werd veelal radiotherapie aanbevolen, uitwendig (aanvankelijk kobalt en later met behulp van een lineaire versneller) of uitwendig gecombineerd met interstitieel (IRT, ook wel brachytherapie genoemd, aanvankelijk met radium, dat al snel werd vervangen door cesium en thans iridium).

De eerste blaasresecties werden na voorbehandeling met uitwendige bestraling uitgevoerd. Geleidelijk aan werd de open radicale cystectomie (ORC), met aansluitend het aanleggen van een urinedeviatie, de gouden standaard, op voorwaarde dat er geen sprake was van verdenking op afstands- of lymfekliermetastasen op de preoperatieve beeldvorming. De radicale cystectomie bestaat bij de man uit het verwijderen van de blaas, inclusief de prostaat, vesiculae seminales en vasa deferentia, en bij de vrouw uit het verwijderen van de uterus, de gehele urethra en de voorwand van de vagina [1-3] (www.oncoline.nl).

De vijfjaarsoverleving van patiënten na radicale cystectomie daalt met het oplopen van het pT-stadium met ziektevrije overlevingscijfers van $72 \%$ bij stadium pT 2 tot minder dan $29 \%$ bij stadium pT4 [4, 5]. Ook de aanwezigheid van lymfekliermetastasen is van invloed op de ziektevrije overleving, waarbij het aantal positieve klieren, de grootte, eventuele extracapsulaire uitbreiding, de uitgebreidheid van de klierdissectie en het totaal aantal gereseceerde klieren belangrijk zijn bij het voorspellen van de overlevingskans [3].

De aanwezigheid van micrometastasen bij het gelokaliseerd (klinisch stadium T2-T4) spierinvasief blaascarcinoom werd de rationale voor (neo)adjuvante chemotherapie
[6]. Bij fitte patiënten met een spierinvasief blaascarcinoom zonder nierfunctiestoornissen kan een op cisplatinum gebaseerde neoadjuvante chemotherapie worden overwogen [2] (www.oncoline.nl).

De radicale cystectomie wordt al jaren als gouden standaard aanbevolen in zowel de Nederlandse, Europese als Amerikaanse richtlijnen. Niettemin ondergaat wereldwijd niet meer dan een derde van de patiënten deze behandeling [7-9]. Uit retrospectieve studies blijkt dat leeftijd en comorbiditeit veelal bepalend zijn om af te zien van cystectomie, alhoewel deze twee factoren juist onafhankelijk blijken te zijn van de kankerspecifieke uitkomsten [10]. Ondanks de goede kankerspecifieke overleving van patiënten die wel geopereerd zijn, gaat de radicale cystectomie gepaard met een significante morbiditeit, en een mortaliteit van 30-90 dagen, zelfs in centra met ervaren operateurs.

Voor een optimale selectie van patiënten is het dan ook van groot belang om gevalideerde meetinstrumenten te hanteren, teneinde onderscheid te kunnen maken tussen fitte en kwetsbare patiënten en niet alleen af te gaan op leeftijd [11]. Voor de oudere patiënt (> 70 jaar) zou een nauwere samenwerking met een geriater behulpzaam kunnen zijn. Naast het besluit in de multidisciplinaire teams willen patiënten in toenemende mate zelf kiezen, uiteraard na optimaal geïnformeerd te zijn, de zogenaamde shared decision making.

Voor patiënten die niet fit genoeg zijn voor een radicale cystectomie of die hun blaas niet kwijt willen, zijn er verschillende alternatieven. In geval van solitaire tumoren met een doorsnee die kleiner is dan $5 \mathrm{~cm},<\mathrm{T} 3 \mathrm{a}$ zonder CIS, is een blaassparende behandeling mogelijk door middel van vier weken uitwendige bestraling (ongeveer zes weken na TURT) gevolgd door brachytherapie. Via een suprapubische incisie worden, door de blaaswand heen, de brachytherapiekatheters geplaatst ten behoeve van de afterloading, waarbij op indicatie ook een partiële cystectomie kan worden uitgevoerd. In geselecteerde patiëntenpopulaties is de kankerspecifieke overleving bij de brachytherapieprocedure vergelijkbaar met die na een cystectomie [12-15]. Er is slechts één studie die een rechtstreekse vergelijking maakt met een (niet-gerandomiseerde) op radicale cystectomie gematcht cohort [15]. Externe radiotherapie alleen is een alternatief dat als oncologisch inferieur wordt beschouwd ten opzichte van de cystectomie [16]. Deze operatie kan tegenwoordig ook middels robotgeassisteerde laparoscopie worden uitgevoerd. Dit geeft een gunstiger postoperatief herstel, een kwalitatief betere afterloading en een op zijn minst vergelijkbare survival $[17,18]$.

Bij spierinvasieve tumoren (T2-T4a) die niet geschikt zijn voor brachytherapie kan een blaassparende behandeling in de vorm van trimodality treatment worden ingezet. Deze behandeling is een combinatie van TURT, uitwendige radiotherapie en chemotherapie, die mogelijk tot betere resultaten leidt [19-21]. 


\section{Radicale cystectomie - de techniek}

Over de ontwikkeling van de techniek van de ORC zijn slechts enkele publicaties beschikbaar. De verschillende vormen van urinedeviatie zijn veel frequenter en nauwkeuriger beschreven. Met de komst van al dan niet robotgeassisteerde laparoscopie werd het nauwkeurig beschrijven zelfs een absolute voorwaarde. De Inspectie voor de Gezondheidszorg stelde dat de veiligheid van de patiënt in deze voorop staat en ziet daar ook op toe [22].

Afgezien van de benaderingswijze, verschillen de chirurgische principes tussen de ORC of de RARC niet wezenlijk. Uiteraard zijn er nog geen langetermijnresultaten van de nieuwere technieken beschikbaar, maar er kunnen wel degelijk verschillen in gevolgen worden aangewezen, zowel ten aanzien van de patiënt als de operateur [23]. Inmiddels hebben de middellange oncologische resultaten (follow-up tot vijf jaar) van enkele cohorten laten zien dat er geen significant verschil is in oncologische overleving ten opzichte van de ORC [24].

De voor- en nadelen, de oncologische en functionele resultaten en de complicaties van de ORC en de RARC worden hierna besproken.

\section{Open cystectomie}

De cystectomie werd vanaf het begin van de vorige eeuw tot eind jaren negentig als een risicovolle operatie beschouwd. Aanvankelijk werd een ORC in geval van een spierinvasief blaascarcinoom alleen uitgevoerd na preoperatieve radiotherapie, of na het in eerste instantie aanleggen van een urinedeviatie, gevolgd door radiotherapie als tweede ingreep. In de oudere literatuur uit de jaren 60 tot 80 van de vorige eeuw lopen de mortaliteitscijfers nogal uiteen, met uitschieters naar $14 \%$. Wereldwijd is de afgelopen decennia de mortaliteit tot ongeveer $2 \%$ gedaald. Perioperatieve bloedtransfusies komen frequent voor (39-62\%) en hebben een ongunstige invloed op het oncologisch resultaat na de cystectomie $[25,26]$. De bloedtransfusiebehoefte is mettertijd verminderd, onder andere door het toenemend gebruik van moderne diathermieapparatuur en het werken met vaste teams (vaak bestaande uit twee urologen). Mede door de introductie van steeds betere sealing and stapling devices kon de ORC niet alleen vlotter worden uitgevoerd, maar trad er tevens minder bloedverlies op [27]. Ook anesthesiologen leverden een bijdrage aan de verminderende transfusiebehoefte door bijvoorbeeld gecontroleerde hypotensie gedurende de gehele ingreep [28] Desondanks bestaat er nog steeds een aanzienlijke perioperatieve morbiditeit, getuige de vroege ( 30 dagen) en late (90 dagen) postoperatieve complicaties, van respectievelijk $44 \%$ en $51 \%$. In de betreffende studies was het niet verrassend dat een hogere
ASA-score geassocieerd bleek met het relatief vaker optreden van vroege complicaties [29]. De ernst van de complicaties varieerde van mild (Clavien-score 1-2) bij 51\% van alle patiënten tot ernstig (Clavien-score 3-5) bij ruim $14 \%$ [30]. Een deel van deze complicaties kwam voort uit de toegepaste technieken voor de ureter-darmanastomosen. Zo werden, ter preventie van reflux, continente reservoirs voorzien van een antirefluxmechanisme. Dit leidde echter tot een hoger risico op afvloedbelemmering, wat uiteindelijk schadelijker bleek dan de negatieve gevolgen van reflux [31]. Ondanks de lage druk die wordt nagestreefd door een gedetubulariseerde darmlis te gebruiken, bleek bacteriurie in een neoblaas een potentiële bron van pyelonefritis. Symptomatische urineweginfectie en urosepsis maken, hoe dan ook, een groot deel uit van de complicaties van al dan niet continente urinedeviaties [32]. Ondanks verbetering in de perioperatieve technieken, is er nog altijd sprake van aanzienlijke morbiditeit.

\section{Robotcystectomie}

$\mathrm{Na}$ de opkomst van de laparoscopische radicale prostatectomie in Nederland (rond de eeuwwisseling) was de stap naar de laparoscopische radicale cystectomie niet groot meer. In 1992 werden door Parra et al. reeds twee niet-radicale cystectomieën uitgevoerd met behulp van laparoscopie [33]. Gill was in 2000 de eerste die, tegelijk met een radicale cystoprostatectomie, een volledig laparoscopisch intracorporeel aangelegde ileumconduit uitvoerde [34]. Rond die tijd werd ook in Nederland het daVinci ${ }^{\mathrm{TM}}$ systeem (Intuitive Surgical ${ }^{\circledR}$ ) geïntroduceerd. Met behulp van dit systeem worden de scoop en de (semi)disposable instrumenten door verschillende armen vastgehouden. Met het $3 \mathrm{D}$ en uitvergrote beeld, in combinatie met de extra vrijheidsgraden van de instrumenten, voert de chirurg vanuit de ergonomisch gevormde afstandsbediening (de console) de operatie uit. Wat echter ontbreekt, is tactiele feedback, hetgeen overigens deels gecompenseerd wordt door het uitvergrote 3D-zicht.

De RARC kan afgerond worden met het intracorporeel dan wel extracorporeel aanleggen van de urinedeviatie. Bij het intracorporeel aanleggen van de deviatie (Bricker- of neoblaas) kan het preparaat bij een vrouw meestal vaginaal verwijderd worden en bij een man middels een minilaparotomie van een van de trocartpoorten of een kleine wisselsnede in de onderbuik. Bij het extracorporeel aanleggen van de deviatie wordt eerst een kleine incisie gemaakt om het preparaat te verwijderen en vervolgens, via deze incisie, een Bricker- of neoblaas gemaakt. Het hechtwerk wordt dan dus buiten de buikholte uitgevoerd. In het geval van een neoblaas wordt de pouch weer in de buikholte gebracht en de buik gesloten, waarna de anastomose robotgeassisteerd wordt gemaakt. Een intracorporele urinedeviatie vergt zeker 
in het begin van de leercurve een langere operatietijd, welke afneemt naarmate de operateur (en het team!) meer ervaring heeft met de ingewikkeldere intracorporele stappen.

In de Nederlandse situatie is het aantal robotgeassisteerde operaties na 2008 sterk toegenomen. Er zijn momenteel op 19 locaties één of meerdere robotsystemen in gebruik. Van de 885 radicale cystectomieën in 2014 werden er 173 $(19,5 \%)$ robotgeassisteerd uitgevoerd op 11 locaties. (www. kwaliteitsregistraties.nl)

\section{Open versus robotgeassisteerde cystectomie}

Dat de discussie over de mogelijke meerwaarde van de RARC boven de ORC nog steeds gaande is, hangt vooral samen met het ontbreken van voldoende prospectieve vergelijkende studies. Bovendien zijn de resultaten op langere termijn op functioneel en oncologisch vlak van de RARC nog niet voorhanden. Verder is de aanschaf van robotapparatuur en het gebruik ervan kostbaar. Ondertussen neemt de expertise echter wel toe, wat is af te lezen aan het toenemend aantal operaties en de soorten operaties in verschillende disciplines waarbij gebruik wordt gemaakt van het robotplatform. "Robot-assisted radical cystectomy (RARC) is feasible... but RARC cannot yet be considered as a standard treatment for invasive bladder cancer." [35] Eerste vereiste voor een mogelijke omslag is dat er hoger niveau van bewijs komt dat aantoont dat de RARC een patiënt voordelen biedt boven de ORC. Is dat bewijs eenmaal geleverd, dan kan worden overwogen om RARC, in een voor laparoscopie toegankelijke populatie, als standaard chirurgische behandeling aan te bieden.

\section{Resultaten van de studies}

Als men de ORC met de RARC wil vergelijken op basis van retrospectieve series, moet er kritisch gekeken worden naar de herkomst van de data, patiëntenselectie, de aantallen operaties per genoemd centrum en naar de jaartallen waarin de operaties plaatsvonden. Zo kan bijvoorbeeld de minder optimale preoperatieve beeldvorming in de vaak oudere ORC-series aanleiding zijn tot het minder adequaat inschatten van het cTNM-stadium. Bovendien zijn de resultaten van de eerste series RARC's sterk beïnvloed door de leercurves van de operateurs. Toch kunnen de retrospectieve studies belangrijke informatie bevatten. Bekend zijn de eerder genoemde voordelen van de RARC ten opzichte van de ORC, minder bloedverlies en transfusiebehoefte, die kunnen worden afgezet tegen de nadelen, een langere operatietijd en hogere kosten. Uit een recentelijk uitgevoerde systematische review van Novara et al., waarin 80 RARC-series en 25 ORC-series met elkaar vergeleken werden, kwam naar voren dat RARC tot significant minder bloedverlies en transfusiebehoefte leidt. Dat gold voor zowel de vergelijkende retrospectieve series als voor de drie prospectieve series met patiëntenaantallen van 20-60 in elke arm [36]. In deze prospectieve gerandomiseerde studies, waarin steeds gebruik werd gemaakt van de extracorporele techniek voor de urinedeviatie in de RARC-groep, bleek er wel sprake van een grote onderlinge spreiding met betrekking tot het bloedverlies. Zo vonden Bochner et al. relatief gemiddeld veel bloedverlies in de RARC-groep (516 ml), en Nix et al. weinig bloedverlies in de open groep $(564 \mathrm{ml})$ [37, 38]. Het verschil in mediane operatieduur in deze prospectieve studies was circa 60 minuten. Daarbij dient vermeld te worden dat de absolute operatietijden in de drie genoemde studies sterk uiteenliepen. Dit zal voor een deel te maken hebben gehad met de verschillen in het al dan niet aanleggen van continente urinedeviaties, die varieerden van 5-55\% [37-39].

In de studie van Bochner et al. van het Memorial Sloan Kettering (MSK) Cancer Center, werd binnen één centrum gerandomiseerd tussen ORC en RARC [37]. De RARC werd uitgevoerd door urologen met ruime ervaring in robotchirurgie in het kleine bekken, maar niet specifiek voor de RARC. Daarnaast werd de deviatie vervolgens extracorporeel door de open chirurgen aangelegd. De interimanalyse liet geen verschil zien in complicaties. Wel viel op dat de kans op ernstige complicaties (Clavien-graad 3-5) $21 \%$ en $22 \%$ was, terwijl de kans in de historische resultaten van ORC in het MSK Cancer Center slechts $13 \%$ was.

Uit een recente review van Novarra et al. blijkt dat de opnameduur voor RARC korter was (gemiddeld negen dagen, spreiding 4,2-16,8) [36]. Daar staat tegenover dat de percentages heropnames in verband met complicaties aanzienlijk bleken. Dertig dagen na operatie waren er bij $44 \%$ van de patiënten complicaties (gemiddeld 11,8 hooggradige complicaties, spreiding 0-35\%) opgetreden, na 90 dagen ging het om 59\% van de patiënten (gemiddeld $15 \%$ hooggradig, spreiding 4 tot 19\%) [36]. De interpretatie van dergelijke getallen behoeft nadere toelichting. Om complicaties werkelijk met elkaar te kunnen vergelijken, zijn prospectieve registraties van complicaties met uniforme scores van essentieel belang. De internationaal meest gebruikte score is de gemodificeerde 5-gradige Clavien-score, verdeeld in diverse categorieën, waarbij graad 3-5 als hooggradig wordt beschouwd. Niet in elke studie werden de complicaties volgens Clavien geregistreerd. Gelukkig is deze score inmiddels ingevoerd in de verplichte registratie van de cystectomieën in Nederland.

De retrospectieve onderzoeken aangaande ORC noemen $64 \%$ complicaties na 90 dagen, waarvan $67 \%$ tijdens de ziekenhuisopname waren opgetreden [30]. Gastro-intestinaalgerelateerde problemen $(29 \%)$ en infecties $(25 \%)$ worden het meest genoteerd, maar urogenitale problematiek $(28 \%)$ staat bovenaan als het gaat om hooggradige complicaties [30]. Voorspellende factoren voor het optreden van complicaties 


\section{Hier staat een advertentie.}

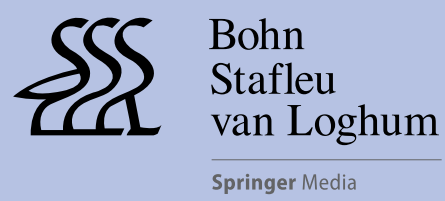

Houten 2015 


\section{Hier staat een advertentie.}

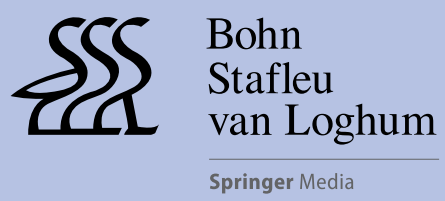

Houten 2015 


\section{Hier staat een advertentie.}

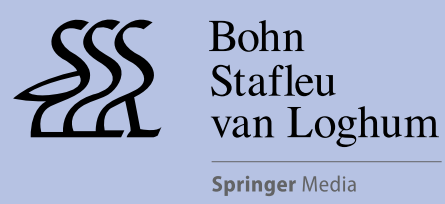

Houten 2015 


\section{Hier staat een advertentie.}

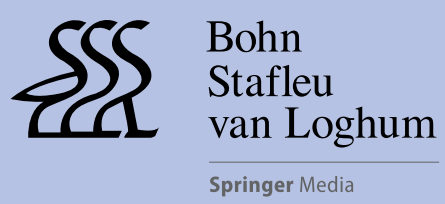

Houten 2015 
in de multivariate analyses van deze studie bleken leeftijd, het geschatte bloedverlies en voorgaande abdominale chirurgie. Ook in de review van de RARC-series bleken leeftijd en geschat bloedverlies voorspellende factoren, met daarnaast de ASA-score, de BMI en het type urinedevatie [36].

Uit een recent verschenen review van Yuh et al. betreffende de oncologische en functionele resultaten van de RARC, bleek dat de lymfeklieropbrengst en de aantallen positieve snijvlakken vergelijkbaar waren met die van de ORC [40]. Opmerkelijk genoeg zijn er aanwijzingen dat recidieven mogelijk een ander patroon van metastaseren tonen bij patiënten die een RARC hebben ondergaan. Zo toonden Nguyen et al. aan dat recidieven bij deze patiënten vaker in lymfeklieren buiten het bekken gelegen waren en vaker ( 21 versus $8 \%$ ) peritoneale carcinomatosa betroffen [41].

Uit een andere review van Raza et al., met 700 patiënten met een status na RARC en een follow-up van meer dan vijf jaar, bleken de recidiefvrije overleving, de ziektespecifieke overleving en de algehele overleving respectievelijk $67 \%$, $75 \%$ en $50 \%$ te zijn. Deze overlevingspercentages komen overeen met die van ORC-series [24].

Om krachtiger bewijs te krijgen, zijn vergelijkende prospectief (gerandomiseerde) multicentrische studies nodig. Een eerste aanzet hiertoe gaven Nix et al., Bochner et al. en Messer et al. [37-39]. Laatstgenoemde beschreef als eerste de kwaliteit van leven in gerandomiseerde groepen van elk 20 patiënten die een ORC, dan wel een RARC ondergingen. Met behulp van gevalideerde vragenlijsten over de kwaliteit van leven werden de resultaten tot 12 maanden na de operatie vergeleken. Met uitzondering van een betere score op het item lichamelijk welbevinden na zes maanden ten faveure van de RARC-patiënten, waren er geen significante verschillen op de andere domeinen. Deze studie vormde de basis voor het tot stand komen van de Amerikaanse multi-institutionele, gerandomiseerde prospectieve noninferiority studie, RAZOR (randomized open versus robotic cystectomy) genaamd, waarin 320 patiënten zullen worden geïncludeerd, met als hypothese dat er geen verschil is in de tweejaars ziektevrije overleving. Secundaire uitkomstmaten zijn complicaties, kwaliteit van leven en functionele resultaten. In de participerende centra voert eenzelfde team na randomisatie hetzij een ORC uit, hetzij een RARC met een extracorporele deviatie. In 2017 worden de eerste resultaten verwacht [42]. Alhoewel de uitspraak van Studer "It is the surgeon that makes the difference, not the instrument" zeer aannemelijk lijkt, zou deze uitspraak in het licht van verdergaande technische ontwikkelingen toch wat te kort door de bocht kunnen zijn [35]. De vraag is of op basis van de huidige studies voldoende bewijs beschikbaar komt over de vraag welke operatie tot een beter resultaat leidt: de ORC of de RARC. Ondertussen dient zich een onophoudelijke stroom aan nieuwe inzichten aan in operatietechnieken, doen robotteams in toenemende mate ervaring op en ontwikkelt zich de expertise van dergelijke teams in hoog tempo. Daarnaast gaat verdere verfijning en uitbreiding van mogelijkheden van robotplatforms dermate snel, dat vergelijkende studies al snel gedateerd zijn. Mogelijk zullen deze factoren een bias vormen in toekomstige prospectieve multicentrische studies. Los van mogelijke voordelen voor de patiënt is er dan ook nog een blijvend ergonomisch voordeel voor urologen die deze operaties nog jarenlang zullen willen uitvoeren, voornamelijk ten opzichte van laparoscopie.

\section{Kosteneffectiviteit}

Naast de zich uitkristalliserende kennis van de resultaten van de RARC speelt de discussie over de kosten een interfererende rol. De aanschaf en het gebruik van een daVinci ${ }^{\mathrm{TM}}$ systeem gaan gepaard met hogere kosten. Er zijn enkele (Amerikaanse) kosteneffectiviteitsstudies gedaan [43-45]. De postoperatieve complicaties brengen de meeste kosten met zich mee. Zo toonde een vergelijkende studie dat het RARC-cohort meer kosten met zich meebracht dan het ORC-cohort, ondanks dat er in de eerstgenoemde studie minder frequent complicaties optraden. Dit kwam doordat vooral laaggradige complicaties minder vaak optraden, waardoor de kostenbesparing minder invloed had [46]. In de genoemde studies zijn overigens geen kostenoverwegingen gemaakt aangaande bijvoorbeeld het vervroegd moeten stoppen van een operateur wegens lichamelijke klachten.

Er moet dan ook een goede kosteneffectiviteitsstudie komen om hier beter inzicht in te krijgen. Dit aspect is van groot belang in de onderhandeling met de zorgverzekeraar, teneinde de behandeling vergoed te krijgen. Momenteel wordt er in Nederland gewerkt aan het opzetten van de RACE-studie (Radicale Cystectomie Evaluatie, www.racestudie.nl) waarvoor ZonMw de subsidieaanvraag reeds heeft gehonoreerd. Het betreft een prospectief vergelijkende studie naar de kosteneffectiviteit van RARC versus ORC. De primaire uitkomstmaat wordt gevormd door complicaties (Clavien-Dindo tot 90 dagen). Secundaire uitkomstmaten zijn ziektegerelateerde kwaliteit van leven (EQ-5D, FACTVanderBilt Bladder Index en Bladder Cancer Index), tijd tot herstel, perioperatieve parameters, bloedverlies, transfusieparameters, duur ziekenhuisverblijf, duur verblijf op de IC, kosten en de pathologische resultaten. De studie zal uitgevoerd worden in 20 hoogvolumecentra ( $>20 /$ jaar), waarbij de RARC-centra de leercurve van ten minste 40 casus moeten hebben doorlopen alvorens te starten met de inclusie. In totaal zal de studie 338 patiënten moeten includeren.

Het definitieve antwoord op de vraag of een radicale cystectomie open of robotgeassisteerd laparoscopisch moet worden uitgevoerd, omdat dit beter is voor de patiënt, zal nog even op zich laten wachten. De techniek schrijdt echter voort. Voor veel urologen lijkt de RARC een aantrekkelijk alternatief voor de ORC. 


\section{Conclusie}

Een uitgebreide lymfeklierdissectie en een ORC met aansluitend het aanleggen van een urinedeviatie is de gouden standaard voor patiënten met een spierinvasief blaascarcinoom (cT2-T4) of een hoogrisico cT1-blaastumor. De RARC is een veilige behandeling die minder bloedverlies geeft, lagere transfusieratio's heeft en mogelijk leidt tot een sneller herstel van de patiënt. Daarnaast heeft de RARC een betere ergonomie voor de operateur dan de ORC, maar is de operatieduur van de RARC langer en zijn er hogere operatiekosten. Het is wenselijk dat er prospectieve studies komen die voldoende bewijskracht kunnen leveren om te kijken of er verschil is tussen de ORC en de RARC op het oncologische en/of functionele vlak.

Open Access This article is distributed under the terms of the Creative Commons Attribution 4.0 International License (http://creativecommons.org/licenses/by/4.0/), which permits unrestricted use, distribution, and reproduction in any medium, provided you give appropriate credit to the original author(s) and the source, provide a link to the Creative Commons license, and indicate if changes were made.

\section{Literatuur}

1. Stenzl A, Cowan NC, De Santis M, Kuczyk MA, Merseburger AS, et al. Treatment of muscle-invasive and metastatic bladder cancer: update of the EAU guidelines. Eur Urol. 2011;59(6):1009-18.

2. Gakis G, Efstathiou J, Lerner SP, Cookson MS, Keegan KA, et al. ICUD-EAU International Consultation on Bladder Cancer 2012: radical cystectomy and bladder preservation for muscle-invasive urothelial carcinoma of the bladder. Eur Urol. 2012;63(1):45-57.

3. Witjes JA, Compérat E, Cowan NC, De Santis M, Gakis G, Lebret $\mathrm{T}$, et al. EAU guidelines on muscle-invasive and metastatic bladder cancer: summary of the 2013 guidelines. Eur Urol. 2014;65(4):778-92.

4. Shariat SF, Karakiewicz PI, Palapattu GS, Lotan Y, Rogers CG, et al. Outcomes of radical cystectomy for transitional cell carcinoma of the bladder: a contemporary series from the Bladder Cancer Research Consortium. J Urol. 2006;176(6 Pt 1):2414-22.

5. Stein JP, Lieskovsky G, Cote R, Groshen S, Feng AC, et al. Radical cystectomy in the treatment of invasive bladder cancer: longterm results in 1,054 patients. J Clin Oncol. 2001;19(3):666-75.

6. Meeks JJ, Bellmunt J, Bochner BH, Clarke NW, Daneshmand S, et al. A systematic review of neoadjuvant and adjuvant chemotherapy for muscle-invasive bladder cancer. Eur Urol. 2012;62(3):523-33.

7. Prout GR, Wesley MN, Yancik R, Ries LAG, Havlik RJ, Edwards BK. Age and comorbidity impact surgical therapy in older bladder carcinoma patients: a population-based study. Cancer. 2005; 104:1638-47.

8. Leliveld AM, Doornweerd BHJ, Bastiaannet E, Schaapveld M, Jong IJ de. Treatment and outcome in muscle invasive bladder cancer: a population-based survey. World J Urol. 2010;28(4):439-44.

9. Goossens-Laan CA, Visser O, Hulshof MCCM, Wouters MW, Bosch JLHRWW, et al. Survival after treatment for carcinoma invading bladder muscle: a Dutch population-based study on the impact of hospital volume. BJU Int 2011;110(2):226-32.

10. Goossens-Laan, CA, Leliveld, AM, Verhoeven, RH, Kil PJ, Bock $\mathrm{GH}$ de, et al. Effects of age and comorbidity on treatment and survival of patients with muscle-invasive bladder cancer. Int J Cancer. 2014;135(4):905-12.
11. Externmann M, Hurria A. Comprehensive geriatric assessment for older patients with cancer. J Clin Oncol. 2007;25:1824-31.

12. Koning CCE, Blank LECM, Koedooder C, Os RM van, Kar M van de, et al. Brachytherapy after external beam radiotherapy and limited surgery preserves bladders for patients with solitary pT1pT3 bladder tumors. Ann Oncol. 2012;23(11):2948-53.

13. Aluwini S, Rooij PHE van, Kirkels WJ, Boormans JL, KolkmanDeurloo I, Wijnmaalen A. Bladder function preservation with brachytherapy, external beam radiation therapy, and limited surgery in bladder cancer patients: long-term results. Int J Radiat Oncol Biol Phys. 2014;88(3):611-7.

14. Van Poppel H, Lievens Y, Van Limbergen E, Baert L. Brachytherapy with iridium-192 for bladder cancer. Eur Urol. 2000;37(5):605-8.

15. Van der Steen-Banasik E, Ploeg M, Witjes JA, Rey FS van, Idema $\mathrm{JG}$, et al. Brachytherapy versus cystectomy in solitary bladder cancer: a case control, multicentre, East-Netherlands study. Radiother Oncol. 2009;93(2):352-7.

16. Kozak KR, Hamidi M, Manning M, Moody JS. Bladder preservation for localized muscle-invasive bladder cancer: the survival impact of local utilization rates of definitive radiotherapy. Int J Radiat Oncol Biol Phys. 2012;83(2):e197-e204.

17. Nap-van Klinken A, Bus SJEA, Janssen TG, Van Gellekom MPR, Smits G, Steen-Banasik E van der. Interstitial brachytherapy for bladder cancer with the aid of laparoscopy. J Contemp Brachytherapy. 2014;6:313-7.

18. Pieters B, Steen-Banasik E van der, Van Limbergen E. The GEC ESTRO Handbook of brachytherapy. In: Limbergen E van, Potter R, Hoskin P, Baltas D, redactie Part II: clinical practice urogenital tract. second. Leuven; 2015. pag. 1-13.

19. Ploussard G, Daneshmand S, Efstathiou J, Herr H, James N, Rödel C. Critical analysis of bladder sparing with trimodal therapy in muscle-invasive bladder cancer: a systematic review. Eur Urol. 2014;66(1):120-37.

20. Mak RH, Hunt D, Shiple WU, Efstathiou JA, Teste WJ, et al. Long-term outcomes in patients with muscle-invasive bladder cancer after selective bladder-preserving combined-modality therapy: a pooled analysis of Radiation Therapy Oncology Group protocols 8802, 8903, 9506, 9706, 9906, and 0233. J Clin Oncol. 2014;32(34):3801-9.

21. Arcangeli G, Arcangeli S, Strigari L. A systematic review and meta-analysis of clinical trials of bladder-sparing trimodality treatment for muscle-invasive bladder cancer. Crit Rev Oncol Hematol. 2015;94:105-15.

22. IGZ. Toetsingskader Follow-up Minimaal invasieve chirurgie ten behoeve van het tweede fase onderzoek vanaf september 2009.

23. Zihni AM, Ohu I, Cavallo JA, Cho S, Awad MM. Ergonomic analysis of robot-assisted and traditional laparoscopic procedures. Surg Endosc. 2014;28(12):3379-84.

24. Raza SJ, Wilson T, Peabody JO, Wiklund P, Scherr DS, et al Long-term oncologic outcomes following robot-assisted radical cystectomy: results from the International Robotic Cystectomy Consortium. Eur Urol. 2015;68(4):721-8.

25. Kluth LA, Xylinas E, Rieken M, El Ghouayel M, Sun M, et al. Impact of peri-operative blood transfusion on the outcomes of patients undergoing radical cystectomy for urothelial carcinoma of the bladder. BJU Int. 2014;113(3):393-8.

26. Linder BJ, Frank I, Cheville JC, Tollefson MK, Thompson RH, Tarrell RF, et al. The impact of perioperative blood transfusion on cancer recurrence and survival following radical cystectomy. Eur Urol. 2013;63(5):839-45.

27. Chang SS, Smith JA, Cookson MS. Decreasing blood loss in patients treated with radical cystectomy: a prospective randomizes trial using a new stapling device. J Urol. 2003;169(3):951-4.

28. Ahlering TE, Henderson JB, Skinner DG. Controlled hypotensive anesthesia to reduce blood loss in radical cystectomy for bladder cancer. J Urol. 1983;129(5):953-4. 
29. Nieuwenhuijzen JA, Vries RR de, Bex A, Poel HG van der, Meinhardt $\mathrm{W}$, Antonini N, et al. Urinary diversions after cystectomy: the association of clinical factors, complications and functional results of four different diversions. Eur Urol. 2008;53(4):834-44.

30. Shabsigh A, Korets R, Vora KC, Brooks CM, Cronin AM, Savage $\mathrm{C}$, et al. Defining early morbidity of radical cystectomy for patients with bladder cancer using a standardized reporting methodology. Eur Urol. 2009;55(1):164-76.

31. Kristjansson A, Mansson W. Renal function in the setting of urinary diversion. World J Urol. 2004;22(3):172-7.

32. Mano R, Baniel J, Goldberg H, Stabholz Y, Kedar D Yossepowitch O. Urinary tract infections in patients with orthotopic neobladder. Urol Oncol. 2014;32(1):50.e9-14.

33. Parra RO, Andrus CH, Jones JP, Boullier JA. Laparoscopic cystectomy: initial report on a new treatment for the retained bladder. J Urol. 1992;148(4):1140-4.

34. Gill IS, Fergany A, Klein EA, Kaouk JH, Sung GT, Meraney AM, et al. Laparoscopic radical cystoprostatectomy with ileal conduit performed completely intracorporeally: the initial 2 cases. Urology. 2000;56(1):26-30.

35. Studer UE. The surgeon makes the difference, not the instrument used. Eur Urol. 2015;67:1051-2.

36. Novara G, Catto JW, Wilson T, Annerstedt M, Chan K, et al. Systematic review and cumulative analysis of perioperative outcomes and complications after robot-assisted radical cystectomy. Eur Urol. 2015;67(3):376-401.

37. Bochner BH, Dalbagni G, Sjoberg DD, Silberstein J, Keren Paz GE, et al. Comparing open radical cystectomy and robot-assisted laparoscopic radical cystectomy: a randomized clinical trial. Eur Urol. 2015;67(6):1042-50.

38. Nix J, Smith A, Kurpad R, Nielsen ME, Wallen EM, Pruthi RS. Prospective randomized controlled trial of robotic versus open radical cystectomy for bladder cancer: perioperative and pathologic results. Eur Urol. 2010;57(2):196-201.

39. Messer JC, Punnen S, Fitzgerald J, Svatek R, Parekh DJ. Healthrelated quality of life from a prospective randomised clinical trial of robot-assisted laparoscopic vs open radical cystectomy. BJU Int. 2014;114(6):896-902.
40. Yuh B, Wilson T, Bochner B, Chan K, Palou J, et al. Systematic review and cumulative analysis of oncologic and functional outcomes after robot-assisted radical cystectomy. Eur Urol. 2015;67:402-22.

41. Nguyen DP, Al Hussein Al Awamlh B, Wu X, O’Malley P, Inoyatov IM, et al. Recurrence patterns after open and robot-assisted radical cystectomy for bladder cancer. Eur Urol. 2015;68(3):399-405.

42. Smith ND, Castle EP, Gonzalgo ML, Parekh DJ, et al. The RAZOR (randomized open vs robotic cystectomy) trial: study design and trial update. BJU Int. 2015;115(2):198-205.

43. Yu HY, Hevelone ND, Lipsitz SR, Kowalczyk KJ, Nguyen PL, et al. Comparative analysis of outcomes and costs following open radical cystectomy versus robot-assisted laparoscopic radical cystectomy: results from the US nationwide inpatient sample. Eur Urol. 2012;61(6):1239-44.

44. Lee R, Chughtai B, Herman M, Shariat SF, Scherr DS. Cost-analysis comparison of robot-assisted laparoscopic radical cystectomy (RC) vs open RC. BJU Int. 2011;108(6):976-83.

45. Mmeje CO, Martin AD, Nunez-Nateras R, Parker AS, Thiel DD, Castle EP. Cost analysis of open radical cystectomy versus robotassisted radical cystectomy. Curr Urol Rep. 2013;14(1):26-31.

46. Leow JJ, Reese SW, Jiang W, Lipsitz SR, Bellmunt J, et al. Propensity-matched comparison of morbidity and costs of open and robot-assisted radical cystectomies: a contemporary populationbased analysis in the United States. Eur Urol. 2014;66(3):569-76.

dr. Anna M. Leliveld, uroloog.

Carl J. Wijburg, uroloog.

Geert A.H.J. Smits, uroloog. 